\title{
Does Meaningful Work Fuel the Altruistic Behavior of Employees in the Contemporary World of Work? Evidence from Private Sector Banks in Sri Lanka
}

\author{
Rochelle Anushini Bartholomeusz ${ }^{1 *}$ \\ Waruni Ayesha Edirisooriya ${ }^{2}$ \\ University of Peradeniya, Sri Lanka ${ }^{1,2}$
}

\begin{abstract}
In the modern era, infinite selfless behavior patterns of employees play a central role in founding a great place of work. But it is hard to expect altruistic behaviors from employees as the game of business is frolicked in a dynamic and competitive arena. Surprisingly, most employees were concerned only about themselves and over-utilized the COVID-19 catastrophe to rationalize their egotistic behaviors. However, scholars found that employees who demonstrate altruistic behaviors are more likely to be optimistic and cheerful than egocentric employees. Hence, employers need to discover appropriate strategies to nurture altruistic behaviors at the workplace. Nowadays, employees have an inner desire to accept tasks, duties, and responsibilities which add more meaning to their work lives. No matter what the situation is, meaningful work can maintain the employee's momentum even during a crisis. Scholars have proved that meaningful work is a significant contributor to altruistic behavior in the workplace. Hence, this study investigated the impact of meaningful work on altruistic behavior with special reference to private sector banking employees in Sri Lanka. Researchers conducted this study in a quantitative perspective along with the positivism philosophy, deductive approach, and survey strategy. Through convenience sampling, data were collected from 149 private sector banking employees in Sri Lanka. Based on the regression analysis, researchers proved that meaningful work could create $34.1 \%$ of an effect on employee's altruistic behavior. Hence, it is evidenced that when employees receive meaningful work, they are intrinsically inspired to exhibit altruistic behaviors at the workplace.
\end{abstract}

Keywords: Altruistic Behavior, Meaningful Work, Private Sector Banking Employees, Sri Lanka

*Corresponding author: Rochelle Anushini Bartholomeusz; Email: rochellebartholomeusz@gmail.com DOI: https://doi.org/10.37227/JIBM-2021-05-831

\section{Introduction}

In a humanitarian world, altruism has become a hallmark. Human beings tend to be altruistic from the inception, which played a crucial role in human evolution and civilization. By nature, altruistic people are more likely to make a favorable difference in someone else's life, accompanied by greater intrinsic satisfaction. But unfortunately, the COVID-19 pandemic has impulsively transformed the world of work (Baker, 2020). During this period of uncertainty and fear, employees tend to alter the way they behave in the workplace. Surprisingly, countless motives can cause an employee to change 
his or her behavior at work (Snezana, 2007). For instance, social distancing, job insecurity, and pay cuts are the apparent motives that have fundamentally changed how employees behave in the workplace. But unfortunately, most of the employers paid less attention to the employees' behavioral changes, which took place during and after the pandemic.

Unlike before, the success or failure of the organization heavily depends on countless behavior patterns of employees. Hence employee behavior can be a blessing or curse (Rosenstiel, 2011). In the organizational setting, employees are responsible for behaving cautiously to respect and establish a solid work culture. These behaviors can be either selfish or selfless (Barasch et al., 2014). Therefore, it is essential to investigate what motivates employees to behave selfishly or selflessly. In general, selfish employees are governed by 'Me First Behaviors', and selfless employees are governed by 'Altruistic Behaviors.' Selfless employees can express his or her empathy and kindness to others by behaving altruistically. Simply, altruistic behavior is a collection of selfless behaviors which encourage individuals to act and react for the betterment of others. Merely, it is the practice of putting others before one's own personal desires and interests. However, in reality, employees can argue whether it is possible to become altruistic at work.

On the other hand, employees are eager to know whether the policies, procedures, values, and principles of the organization encourage altruism. For instance, some employees believe that they have been recruited to serve the organization and not for charity (Singh, 2018). Some employees become altruistic only when the other party requests help. In contrast, some employees are proactive and start to behave altruistically as soon as they realize the other party needs help. With this scenario, inspiring employees intrinsically to exhibit altruistic behaviors at work is a challenge.

In the modern era, none of the employees prefer to be eight to five robots at work. Most of them are eager to know the purpose of their job and the direct and indirect impact of their career on others. Unlike before, employees in the twenty-first century expect their work to be meaningful rather than just a source of income (Lysova et al., 2018). As a result, employees started to value meaningful work above other work conditions such as pay, working hours, promotions, or job security (Cascio, 2003). Employees realize their job is meaningful only when their behaviors, values, and principles match the tasks, duties, and responsibilities they perform (Chalofsky, 2003). If employees acknowledge that their contribution is significant and worthy to the organization and society, they recognize that their work is meaningful. When employees engage in meaningful work, they can explain why they work and for what they perform. At the same time, they feel confident enough to answer the question, 'why am I working beyond the salary paid for me?' With this scenario, scholars such as Michaelson et al. (2013) connected meaningful work to organizational outcomes such as altruistic behavior, job satisfaction, and employee motivation.

According to Agarwal (2016), the competition among private sector banking employees is much higher than employees in the public sector. Due to this severe competition, private sector employees tend to help each other because they believe if they do so, their opportunity to succeed might reduce. Hence, private sector banking employees are less likely to sacrifice their success on behalf of others. Further, this might be the prominent reason which discourages private sector banking employees from performing altruistic behaviors at the workplace (Agarwal, 2016). Hence, banks cannot smoothly execute their operations without altruistic employees (Akwaowo et al., 2018). On the other hand, most employees are willing to show their altruistic behaviors only at strategic times (Hui et al., 2000). For instance, some employees are eager to demonstrate their altruistic behaviors only until they get the promotion, and afterward, they avoid becoming altruistic. This means employees are compelled to help others only when there is a direct external reward. But, employees who genuinely involve in altruistic behaviors are more likely to help others even after the promotion (Hui et al., 2000).

To activate altruistic behavior, individuals must have the ability and motivation to demonstrate such type of behavior. It will be a problem if the employee doesn't have the required level of interest, desire, and enthusiasm to help others. With this scenario, Charoensukmongkol et al. (2015) found that employees who recognize that their job is meaningful to them are more likely to sacrifice their comforts and interests on behalf of others. If employees receive meaningful work, they are more likely to exhibit altruistic behaviors at the workplace. However, regardless of the growing 
attention on the topic 'altruism,' the impact of meaningful work on altruistic behavior is yet to be determined. Further, there is scant evidence from the Sri Lankan context up to date linking meaningful work and altruistic behavior with especial reference to the private sector banking employees. To fulfill the above-mentioned contextual deficiency doing more research on meaningful work and altruistic behavior together is vital.

\section{Research Question}

Does meaningful work positively impacts the altruistic behavior of private sector banking employees in Sri Lanka?

\section{Research Objective}

To investigate the positive impact of meaningful work on altruistic behavior of private sector banking employees in Sri Lanka

\section{Significance of the Study}

Primarily, the results of this study favorably contributed to the prevailing literature as meaningful work and altruistic behavior of employees are emerging concepts that need more empirical support (Buss, 2008). On the other hand, banks try their level best to offer a high-quality service to all their customers and Akwaowo et al. (2018) found that banking employees who demonstrate altruistic behaviors play a prominent role in this regard. When an employee behaves altruistically, it, directly and indirectly, inspires the rest of the employees to act in the same manner. This enables to establish a helpful and altruistic work culture in the organization. On the other hand, employees get the opportunity to enhance their unique skills, behaviors, and interpersonal relationships related to personal and professional life. Further, when employees are inspired by altruism, they are less likely to focus on their status and reputation. They genuinely become altruistic even it is costly to them. Further, according to Ferrin et al. (2006) altruistic behaviors provide opportunities for organizational members to cultivate mutual trust and to establish solid emotional bonds with each other. This enables employees to reduce unnecessary interpersonal conflicts at the workplace.

\section{Meaningful Work}

\section{Literature Review}

Physically and psychologically, people want to a live meaningful life (Michaelson et al., 2014). Within the organizational context, work becomes meaningful when the individual believes that his or her work is driven by a clear purpose and effectively contributes to the betterment of the organization (Rosso et al., 2010) Simply, employees tend to believe that the tasks, duties, and responsibilities that they perform are remarkable and valuable (Blanca, et al., 2017). Though there is a meaning in each job, it does not mean it is meaningful (Rosso et al., 2010). Therefore, meaningfulness refers to the level of significance associated (Blanca, et al., 2017) and justification of the work performed by an individual concerning the job (Chalofsky, et al., 2009). Individuals who believe that their work is meaningful experience satisfaction and happiness to a greater extent (Allan et al., 2016). As a whole, meaningful work helps to create a long-lasting dedicated workforce in the organization (Steger, et al., 2009).

\section{Altruistic Behavior}

Eisenberg (1982) viewed altruistic behavior as an intentional discretionary behavior, and people who exhibit altruistic behaviors are intrinsically motivated to help others even without rewards. According to Batson et al., (2011), altruistic behavior can be defined as any favorable behavior that can enhance the wellbeing of another, and there is no expectation of tangible or intangible reward in return. Such behaviors are impulsive and intuitive (Zaki, et al., 2013). In other words, this behavior tends to promote the desires and interests of others (Radovanović, 2018). Smith et al. (1983) highlighted some examples related to altruistic behaviors such as helping employees who got absent from work, 
inducting employees who recently joined the organization, supporting employees who cannot meet the deadline, and who have heavy workloads.

Further, in the organizational context, it has been identified that individuals who do not exhibit altruistic behaviors are inactive and uncooperative (Egilmez, 2017). These kinds of helping behaviors are governed by social and interpersonal concepts related to extra-role behavior (Filkowski et al., 2016). Hence, altruistic behavior is somewhat similar to prosocial behavior (Snyder, et al., 2013). On the other hand, individuals who value altruism are more likely to sacrifice their own aspirations and comforts for the betterment of others (Kaplan, 2000). Such people are concern about the rights and welfare of others while showing compassion for them (Penner, et al., 1998). However, altruistic behavior can vary based on the situation and nature of the individual, along with social, cultural, and psychological aspects (Kurzban et al., 2015). For instance, Accra and Odinioha (2014) found that employees who work for domestic aviation companies in Nigeria are more likely to exhibit altruistic behaviors, and that might be because African countries acknowledge collectivist culture.

\section{Meaningful Work and Altruistic Behavior}

According to the social exchange theory, individuals consciously or unconsciously form relationships by evaluating the costs and benefits. At this point, each individual tries to maximize his or her benefits. With this notion, social exchange theory claims that people tend to demonstrate altruistic behaviors only when they realize that they can gain more benefits compared to costs from the relationship (Yusof, 2018). Hence, in this particular relationship, the behavior of one party depends on the behavior and actions of the other party. Simply the exchanges are mutually interdependent. Directly or indirectly, in return, employees expect certain rewards such as meaningful work from the employer to demonstrate altruistic behaviors at the workplace. Employees who recognize that their job is meaningful to them are more likely to dedicate themselves on behalf of others (Charoensukmongkol et al., 2015) since; those employees have an emotional bond with them (Van Dyne, et al., 2004). Therefore, employees who believe that their work is meaningful are eager to help others by sacrificing their resources and comforts. Nasurdin et al. (2013) found that meaningful work can account for $33.8 \%$ of the variance in altruistic behavior of private sector academic staff members in Malaysia. Even Yusof et al. (2018) found that meaningful work has a significant impact on altruistic behavior $(\beta=0.146, \mathrm{p}<0.05)$ of nurses of a public hospital in Malaysia. Therefore,

$\mathbf{H}_{1}$ : Meaningful work positively impacts the altruistic behavior of private sector banking employees in Sri Lanka.

\section{Research Methodology}

Researchers carried out a quantitative study along with the positivism philosophy, deductive approach, and survey strategy to fill the study's contextual gap. The population for the study was private sector banking employees in Sri Lanka. Through the convenience sampling method, researchers obtained responses from 149 private sector banking employees in Sri Lanka. The researcher adopted the convenience sampling method since the population was too large and due to absence of a sampling frame for banking employees in Sri Lanka. Overall data has been gathered using a standard questionnaire. The questions related to meaningful work were obtained from 21 items of spirituality at work scale by Milliman et al. (2003). The questions related to altruistic behavior were obtained from 24 Organizational Citizenship Behavior scale items by Podsakoff et al. (1997). The Cronbach's alpha value for meaningful work was 0.757 and for altruistic behavior was 0.721 . The hypothesis of the study was tested using regression analysis with the use of SPSS version 20. 


\section{Results and Analysis}

\section{Respondents Profile}

In this study, most of the participants were female banking employees, and as a percentage, it was $52.3 \%$. Based on the age category, the majority of the respondents were between 20-29 years, and as a percentage, it was $61.1 \%$. Moreover, based the job position, majority of the respondents were banking assistants $(42.3 \%)$ during the period of the study.

\section{Hypothesis Testing}

Based on Table 1, the correlation coefficient value $(R)$ of meaningful work was 0.584 , which means there was a moderate positive correlation between meaningful work and altruistic behavior. Based on the R square value (0.341), meaningful work can account for $34.1 \%$ of the variance in altruistic behavior. According to the ANOVA Table 2, the Sig value was 0.000 (less than 0.05 ), and F value was 75.915, and it showed the goodness of fit. This indicated that meaningful work could significantly predict altruistic behavior of private sector banking employees in Sri Lanka. Further, the linear regression equation was derived using the coefficient Table 3, and it was statistically significant (Altruistic Behavior $=1.941+0.534 *$ Meaningful Work). When meaningful work is increased by one unit, altruistic behavior of employees is increased by 0.534 units. With the above finding, researchers accepted the alternative hypothesis of $\mathrm{H}_{1}$ where, "Meaningful work positively impacts the altruistic behavior of private sector banking employees in Sri Lanka".

Table 1: Model Summary

\begin{tabular}{ccccc}
\hline Model & R & R Square & Adjusted R Square & Std. Error of the Estimate \\
\hline 1 & $.584^{\mathrm{a}}$ & .341 & .336 & .36559 \\
\hline
\end{tabular}

a. Predictors: (Constant), Meaningful Work

Table 2: ANOVA

\begin{tabular}{llccccc}
\hline & Model & Sum of Squares & df & Mean Square & F & Sig. \\
\hline 1 & Regression & 10.147 & 1 & 10.147 & 75.915 & $.000^{\text {a }}$ \\
& Residual & 19.648 & 147 & .134 & & \\
& Total & 29.794 & 148 & & & \\
\hline
\end{tabular}

a. Predictors: (Constant), Meaningful Work

b. Dependent Variable: Altruism

Table 3: Coefficients

\begin{tabular}{|c|c|c|c|c|c|c|}
\hline \multirow{2}{*}{\multicolumn{2}{|c|}{ Model }} & \multicolumn{2}{|c|}{ Unstandardized Coefficients } & \multicolumn{2}{|l|}{$\begin{array}{l}\text { Standardized } \\
\text { Coefficients }\end{array}$} & \multirow[b]{2}{*}{ Sig. } \\
\hline & & $\mathrm{B}$ & Std. Error & Beta & $\mathrm{t}$ & \\
\hline \multirow[t]{2}{*}{1} & (Constant) & 1.941 & .236 & & 8.222 & .000 \\
\hline & Meaningful Work & .534 & .061 & .584 & 8.713 & .000 \\
\hline
\end{tabular}

a. Dependent Variable: Altruism

\section{Discussion and Implications}

This positive impact of meaningful work on altruistic behavior of employees was in line with the findings of the previous studies. For instance, Gupta et al. (2014) conducted a study to investigate the relationship between workplace spirituality and organizational citizenship behavior of employees related to insurance industry in India. In that study scholars found that meaningful work which was a dimension of workplace spirituality has a significant positive impact on altruistic behavior of employees. Even Shasavary et al. (2016) conducted similar research and found that meaningful work has a favorable effect on altruistic behavior of employees of Sepah Bank in Esfahan. Further, Kazemipour and MohdAmin (2012) found a moderate positive relationship between meaningful work and altruistic behavior with special reference to 305 Iranian nurses in four public hospitals. This indicated that nurses who receive meaningful work tend to demonstrate more altruistic 
behaviors at the workplace. Similarly, Ahmadi et al. (2014) found 0.695 as correlation coefficient between meaningful work and altruistic behavior among teachers in Iran. Further, study conducted by Charoensukmongkol et al. (2015) discovered the contribution of meaningful work on altruistic behavior with the support of undergraduate and graduate students from two public universities in South Texas. 179 students were used for this study and finally proved that meaningful work is positively associated with altruistic behavior.

The findings of the present study offered an additional contribution to the existing literature as meaningful work and altruistic behavior are trending concepts that require more empirical support. Though plenty of studies have carried on how to improve altruism at work, there is scant evidence on how meaningful work can uplift the altruistic behaviors of employees. Hence, through this study, the industry experts can understand what meaningful work is and how it can be utilized as a costeffective strategy to stimulate and nurture altruistic behaviors at the workplace. Today majority of the employees believe that their work should be a calling one. The reason is in the contemporary world of work, employees acknowledge and value "meaningful work" ahead of all other financial benefits.

The employees who feel that their job is not meaningful will probably be reluctant to demonstrate altruistic behaviors at work. Thus, supporting employees to find meaning in what they do is crucial for an organization's success. For instance, it is vital to make employees aware of how their job benefits others. From this study, employers will get the opportunity to rethink what makes work meaningful and the strategies that can be utilized to create meaningful jobs for their employees. Every employee needs to be connected with the company's overall vision and clearly explain how they contribute to the company's overall success. In other words, management should help their employees realize the importance of their role to the organization. Most importantly, HR professionals and the organization's management need to provide various opportunities for employees to practice altruistic behaviors within the bank. Probably the employers need to understand the importance of introducing altruism to the bank's corporate culture. Further, such altruistic concepts need reflect from the company's policies, procedures, and practices on a daily basis.

\section{Limitations of the Study}

Since it was a quantitative study, respondents received only limited options, and those options were based on the selections made by the researcher. And for this study, data were gathered only at one particular time. Therefore, the researcher was unable to examine the progress of altruistic behaviors of employees before and after providing meaningful work to them. The researcher failed to obtain a sample frame for private sector banking employees in Sri Lanka based on confidentiality and privacy issues. Therefore, researchers had to follow the convenience sampling technique. Further researchers of the present study couldn't study the effect of meaningful work on altruistic behavior using a mediating or moderating variable.

\section{Directions for Future Research}

Previously, the association between meaningful work and altruistic behavior has been widely investigated in a more quantitative perspective. Hence, future academics can continue the same research from a qualitative aspect because concepts such as meaningful work and altruistic behavior are highly subjective. Further, it can be done as a longitudinal study in order to get a better understanding on employees' altruistic behavior before and after providing meaningful work. In addition, the same research can be conducted either for public sector banking employees separately or as a comparative study using both public and private sector banking employees by incorporating probabilistic sampling methods. And also this can be done to another industry such as education, health, apparel and tourism in Sri Lanka. Further, the effect of meaningful work on altruistic behavior considered here is more straightforward. Hence future researchers can investigate the impact of meaningful work on altruistic behavior of employees by including a moderating or mediating variable. 


\section{Conclusion}

The fundamental objective of this study was to examine whether meaningful work has a significant positive impact on altruistic behavior of private sector banking employees in Sri Lanka. Based on the findings researcher concluded that meaningful work could account for $34.1 \%$ of the variance in altruistic behavior of private sector banking employees in Sri Lanka. The findings of this study were in line with Charoensukmongkol et al. (2015), Nasurdin et al. (2013), and Yusof et al. (2018). This means altruistic behavior of employees can be enhanced through meaningful work. In reality, organizations expect altruistic behaviors from their employees. In return, it is the management's responsibility to motivate employees to exhibit altruistic behaviors by giving meaningful tasks, duties, and obligations irrespective of the job position.

\section{References}

Accra, J. S., \& Odinioha, G. J. (2014). Employees Altruism and Organizational Adaptation in Nigeria, Advances in Research, 2(12), 1054-1064

Agarwal, S. (2016). Organizational Citizenship Behavior: A Comparative Study between Public and Private Sector Bank, International Journal of Engineering Technology, 4(5).

Akwaowo, E. R., Eketu, C. A., \& Needorn, R. S. (2018). Human Capital Development and Workers' Altruistic Behavior in Deposit Money Banks in Port Harcourt, International Journal of Advanced Academic Research, 4(5), 129-151

Allan, B. A., Dexter, C., Angel, R., \& Parker, S. (2016). Meaningful work and mental health: job satisfaction as a moderator, Journal of Mental Health, 27(1), 1-7

Baker, M. (2020). Future of Work Trends Post-COVID-19, [Online] Available at: https://www.gartner.com/smarterwithgartner/9-future-of-work-trends-post-covid-19/

Barasch, A., Levine, E., Berman, J. Z. \& Small, D. A. (2014). Selfish or selfless? On the signal value of emotion in altruistic behavior, Journal of Personality and Social Psychology, 107(3), 393413

Batson, C. D., Ahmad, N., \& Stocks, E. L. (2011). Four forms of prosocial motivation: Egoism, altruism, collectivism, and principals. In D. Dunning (Ed.), Social motivation. New York, NY: Psychology Press, 103-126

Blanca, G., \& Ramona, T. (2017). What Makes Work Meaningful, Studies in Business and Economics, 12(2), 46-52

Buss, D. M., (2008). The Evolution of Desire-Revised. New York, NY: Basic books.

Cascio, W. F. (2003). Responsible restructuring: Seeing employees as assets, not costs, Ivey Business Journal, 68, 1-5

Chalofsky, N. (2003). An emerging construct for meaningful work, Human Resource Development International, 6(1), 69-83.

Chalofsky, N., \& Krishna, V., (2009). Meaningfulness, commitment, and engagement: The intersection of a deeper level of intrinsic motivation, Advances in Developing Human Resources, 11(2), 189-203

Charoensukmongkol, P., Daniel, J. L., \& Jardon, R. C. (2015). The Contribution of Workplace Spirituality on Organizational Citizenship Behavior, Advances in Business Research, 6, 3245

Egilmez, E. (2017). Altruism and Popularity, International Journal of Educational Methodology, $3(2), 65-74$

Eisenberg, N. (1982). The development of reasoning regarding prosocial behavior. In N. Eisenberg (Ed.), The development of prosocial behavior. New York, NY: Academic Press, 219-249

Eldakar, O. T. \& Wilson, D. S. (2008). Selfishness as second-order altruism, Proceedings of the National Academy of Sciences, 105(19), 6982-6986

Ferrin, D. L., Dirks, K. T., \& Shah, P. P. (2006). Direct and indirect effects of third-party relationships on interpersonal trust, Journal of Applied Psychology, 91(4), 870-883

Filkowski, M. M., Cochran, R. N. \& Haas, B. W. (2016). Altruistic behavior: mapping responses in the brain, $5,65-75$ 
Gupta, M., Kumar, V., \& Singh, M. (2014). Creating satisfied employees through workplace spirituality: A study of the private insurance sector in Punjab (India). Journal of business ethics, 122(1), 79-88

Hui, C., Lam, S. S. K., \& Law, K. (2000). Instrumental Values of Organizational Citizenship Behavior for Promotion: A Field Quasi-Experiment, Journal of Applied Psychology, 85(5), $822-828$

Kaplan, S. (2000). Human nature and environmentally responsible behavior, Journal of Social Issues, 56(3), 491-505

Kurzban, R., Burton-Chellew, M. N., \& West, S. A., (2015). The Evolution of Altruism in Humans, Annual Review of Psychology, 66, 575-599

Lehtonen, T. (2019). Selflessness in Wage Work: A Possibility or an Oxymoron?, Workplace Communication II, 10, 39-52

Lysova, E. I. et al. (2018). Fostering meaningful work in organizations: A multi-level review and integration, Journal of Vocational Behavior, 110, 374-389

Michaelson, C., Pratt, M. G., Grant, A. M., \& Dunn, C. (2014). Meaningful Work: Connecting Business Ethics and Organization Studies, Journal of Business Ethics, 121(1), 77-89

Milliman, J., Czaplewsk, A., \& Ferguson, J. (2003). Workplace spirituality and employee work attitudes, Journal of Organizational Change Management, 16(4), 426-447

Nasurdin, A. M., Nejati, M., \& Mei, Y. K. (2013). Workplace spirituality and organizational citizenship behaviour: Exploring gender as a moderator, South African Journal of Business Management, 44(1), 61-74

Penner, L. A., \& Finkelstein, M. A. (1998). Dispositional and structural determinants of volunteerism, Journal of Personality and Social Psychology, 74, 525-537

Podsakoff, P., Ahearne, M., \& MacKenzie, S. (1997). Organizational citizenship behavior and the quantity and quality of work group performance, Journal of Applied Psychology, pp. 82(2), 262-270

Post, S. G., Underwood, L. G., Schloss, J. P., \& Hurlbut, W. B. (2002). Altruism and altruistic love: Science, philosophy, and religion in dialogue, Oxford University Press.

Radovanović, B. (2018). Altruism in Behavioural, Motivational and Evolutionary Sense, Philosophy and Society, 30(1), 122-134

Rosenstiel, L. (2011). Employee Behavior in Organizations, On the Current State of Research, 22(4), 344-366.

Rosso, B. D., Dekas, K. H., \& Wrzesniewski, A. (2010). On the meaning of work: A theoretical integration and review, Research in organizational behavior, 30, 91-127

Singh, N. (2018). The Magic of Altruism in the Workplace. Retrieved. [Online] Available at: https://www.drnadine.com/post/the-magic-of-altruism-in-the-workplace

Smith, C. A., Organ, D. \& Near, J. P., (1983). Organizational citizenship behavior: Its nature and antecedents, Journal of Applied Psychology, 68(4), 653-663

Snezana, M. (2007). Motivation of Employees and Behavior Modification in Health Care Organizations, Acta Medica Medianae, 46(2), 53-61

Snyder, M., \& Patrick, C. D. (2013). Altruism and Prosocial Behavior in Theodore Millon, Melvin Lerner and Irving Meiner (eds). Handbook of Psychology: Personality and Social PsychologyNew Jersey: John Wiley and Sons, Inc, 467-485

Steger, M. F., \& Dik, B. J. (2009). If one is looking for meaning in life, does it help to find meaning in work?, Applied Psychology: Health and Well-Being, 1(3), 303-320

Van Dyne, L., \& Pierce, J. L., (2004). Psychological ownership and feelings of possession: three field studies predicting employee attitudes and organizational citizenship behavior, Journal of Organizational Behavior, 25(4), 439-459

Yusof, J., Yaacob, H. F., \& Rahman, S. A. A. (2018). The Relationship of Workplace Spirituality on Organizational Citizenship Behaviour, Sains Humanika, 10(2), 31-39

Zaki, J., \& Mitchell, J. P. (2013). Intuitive pro-sociality, Current Directions in Psychological Science, $22(6), 466-470$ 